\title{
Assessing nutrition in the critically ill elderly patient: A comparison of two screening tools
}

\author{
Swagata Tripathy, J. C. Mishra ${ }^{1}$
}

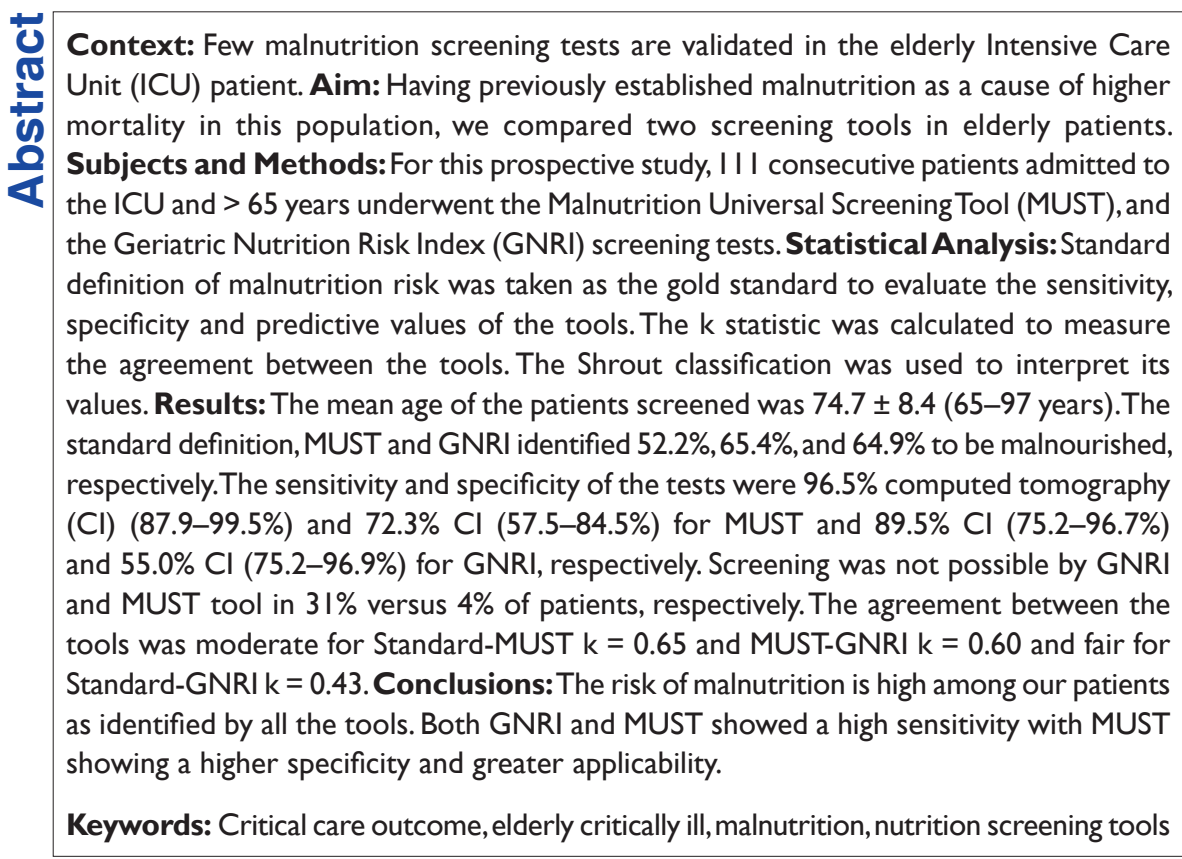

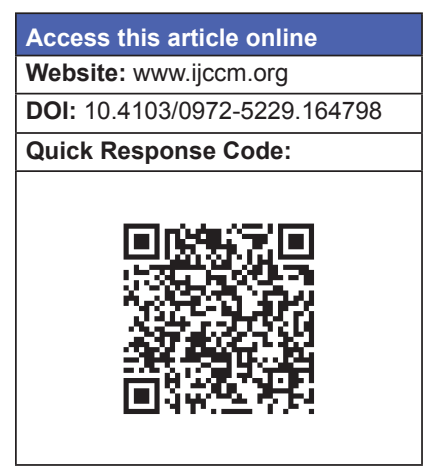

\section{Introduction}

Malnutrition among patients admitted to the Intensive Care Unit (ICU) is known to be associated with greater mortality and morbidity. ${ }^{[1]}$ The elderly patient is known to have reduced appetite, longer periods of illness, duration of hospital stay, higher infection rates, and delayed wound healing. ${ }^{[2]}$ Malnutrition is not readily recognizable or distinguishable from the changes of the aging process, which means that a significant percentage of cases are undiagnosed. ${ }^{[3]}$ In a previous study, we have observed

From:

Department of Trauma and Emergency Medicine (Critical Care), All India Institute of Medical Sciences (AIIMS), Bhubaneswar, ${ }^{1}$ Department of Anaesthesia, Kalinga Institute of Medical Sciences,

Bhubaneswar, Odisha, India

\section{Correspondence:}

Dr. Swagata Tripathy, Department of Trauma and Emergency Medicine (Critical Care), All India Institute of Medical Sciences (AlIMS),

Bhubaneswar, India.

E-mail: tripathyswagata@gmail.com that up to $68 \%$ of critically ill elderly patients in our ICUs may be at a risk of being malnourished and that this significantly increases long-term mortality. ${ }^{[4]}$

Nutritional status assessment of the critically ill patient is performed to classify nutritional status, identify nutritional risk, and to serve as a baseline for monitoring nutrition support adequacy. Many scores or assessment

This is an open access article distributed under the terms of the Creative Commons Attribution-NonCommercial-ShareAlike 3.0 License, which allows others to remix, tweak, and build upon the work non-commercially, as long as the author is credited and the new creations are licensed under the identical terms.

For reprints contact: reprints@medknow.com

How to cite this article: Tripathy S, Mishra JC. Assessing nutrition in the critically ill elderly patient: A comparison of two screening tools. Indian J Crit Care Med 2015;19:518-22. 
tools are available for the assessment of nutrition risk. ${ }^{[5-10]}$ Having mostly been developed and validated in outpatient or inpatient settings, ${ }^{[8]}$ there are few scores available for being used among the geriatric critically ill population where it may be the most beneficial. We aimed to compare the applicability, effectiveness, and utility of two easy to use nutrition screening tests in this population.

\section{Subjects and Methods}

\section{Patient selection}

All patients $>65$ years of age admitted consecutively to the 12 bedded mixed medical-surgical ICU of a tertiary care hospital were included in this study. Duration of ICU stay had to be more than $24 \mathrm{~h}$. The ICU caters to all patients except postcardiac and neurosurgery under a certified intensivist cover. Average annual patient admission rate is $>700$ and the average length of stay 3.5 days. The nurse to patient ratio is 1:1 for ventilated and 1:2-3 for non-ventilated patients. Patients opting for care limitation/withdrawal within $24 \mathrm{~h}$, admitted after elective surgery for $<24 \mathrm{~h}$, and those admitted after cardiac arrest were excluded. After approval by the hospital ethical committee and review board, the patient or a close family member gave consent to participate in a larger study from of which this data were a part. ${ }^{[4]}$

\section{Nutritional status}

The prevalence of risk of malnutrition was measured by using a preset definition of malnutrition; this definition has been used widely in similar studies involving other patient groups and allows of comparability among studies and scores. ${ }^{[11-14]}$ Patients were defined to be at a severe risk of malnutrition when the following conditions were present: Body mass index $(\mathrm{BMI})<20 \mathrm{~kg} / \mathrm{m}^{2}$ and an unintentional weight loss of more than $5 \%$ during the last 3 months. Patients were defined to be at a moderate risk if they had more than $5-10 \%$ unintentional weight loss during the last 6 months, independent of BMI.

Patients were weighed by a few trained members of the nursing staff. The ICU has its own set of scales, which are calibrated annually or sooner if needed, by an external agent. Patients were asked to recall their height or were measured by the admitting nurse using a free-standing measuring rod. In patients who were unable to stand or be weighed, height and weight were estimated using ulnar length or knee lengths measurements, as per protocol. On admission, patients or relatives were asked to report any unplanned weight loss.

Using these data, the scores were calculated by the admitting nurse, as part of normal admissions procedure within the first $24 \mathrm{~h}$ of admission to the ICU. Each patient was categorized into a low, medium, or high-risk group of malnutrition by the investigator.

\section{Screening tests}

Malnutrition Universal Screening Tool (MUST) is a five-step screening tool to identify adults, who are malnourished, at risk of malnutrition (undernutrition), or obese. It also includes management guidelines which can be used to develop a care plan. ${ }^{[10]}$ It is for use in hospitals, community and other care settings and can be used by all care workers. A considerable amount of work has been undertaken to validate MUST. The practicality and predictive validity for mortality and length of stay of "MUST" in a group of acutely ill hospitalized elderly patients and its ability to screen all of the elderly patients including those who can and cannot be weighed has been demonstrated. ${ }^{[15-17]}$

The Geriatric Nutrition Risk Index (GNRI) index is a modification of the Nutritional Risk Index in which the value of "normal weight patients" replaces the original formula of "ideal weight patients" (calculated from Lorentz's formula) to be applied in the geriatric population. ${ }^{[9,18]}$ This index takes into account two main parameters: Serum albumin and the ratio between the current weight and ideal weight of the individual.

\section{Statistical analysis}

Standard descriptive statistical methods were used to express means, standard deviations, percentages, frequencies, and minimum and maximum values. Cross-tabulations were used to present sensitivity, specificity and positive and negative predictive values. A 95\% confidence interval was assessed. Multiple imputations by assuming missing at random was applied to predict missing values. Statistical analyses were performed using the SPSS-system for Windows, version 21.0 (SPSS, Chicago, IL, USA). MUST and GNRI classify patients into three categories. To compare the tools and their agreements, the results were organized into two variables: No risk for malnutrition (MUST - 0 and GNRI - low risk) and at risk of malnutrition (MUST - 1, 2 and GNRI - medium and high). The predefined standard definitions of malnutrition risks were taken as the gold standard to evaluate the sensitivity, specificity, and predictive values of the tools. The k statistic was calculated to measure the agreement between the tools and the Shrout classification was used to interpret its values as follows - 0-0.1: Virtually none; 0.11-0.4: Slight; 0.41-0.6: Fair; 0.61-0.8: 
Moderate; and 0.81-1.0: Substantial. ${ }^{[19,20]}$

\section{Results}

A total of 250 patients $>65$ years of age were admitted to the ICU during this period of which 111 (80 males, 31 females) were included in the analyses. The exclusion was by predefined criteria (105), or when the data required for assessing nutrition status by the preset definition was incomplete (24). The mean age was $74.6 \pm 8.2$ years (65-97 years), mean Acute Physiology and Chronic Health Evaluation II (APACHE) II was $19.1 \pm 6.5 \mathrm{SD}$, and mean BMI was $22.7 \pm 2.2 \mathrm{~kg} / \mathrm{m}^{2}$ (range $\left.15-34 \mathrm{~kg} / \mathrm{m}^{2}\right)$. The mean length of stay was $7.2 \pm 3.3 \mathrm{SD}$. There was a predominance of medical over surgical indications for admission [Figure 1].

The data for MUST was complete for $96 \%$ and GNRI in $70.3 \%$ of the patients. The large percentage of missing GNRI data were due to missing weight measurements. $52.3 \%, 63 \%$, and $65 \%$ were at risk of malnutrition by the preset definition, MUST and GNRI, respectively. Patients at nutritional risk had a longer length of stay in the ICU (7.5 vs. 6.11 days). The nutrition status significantly affected the long-term mortality at 1-year: Log-rank (Mantel-Cox) $P=0.010$ [Figure 2]. ${ }^{[4]}$ Table 1 shows the sensitivities, specificities, positive and negative predictive values of the comprehensive malnutrition screening tools. The agreement between the tools was moderate for Standard-MUST k $=0.65$ and MUST-GNRI $\mathrm{k}=0.60$ and fair for Standard-GNRI $\mathrm{k}=0.43$.

\section{Discussion}

In what we understand to be the first study of its type, we compared two easy to use nutrition screening tools

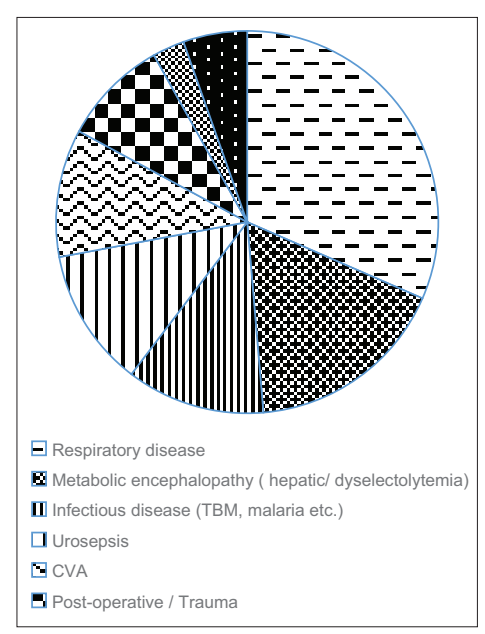

Figure I: Distribution of disease $n=1 \mathrm{I}$ in critically ill elderly patients. We found the prevalence of malnutrition to be high, and both MUST and GNRI to have a high sensitivity with the former performing better and being easier to implement (lesser missing values). The greater incidence of missing values in the GNRI tool stems from an inherent difference in weight calculation of the patient by the two tools: MUST provide a nomogram for the estimation of BMI from mid arm circumference if weight cannot be measured in a critically sick patient - GNRI has no alternatives to actual weight measurement. In ICUs with beds having inbuilt weighing scales, this problem may be mitigated.

There is a wide variation in the methods of nutrition screening of acutely ill patients: Most have not been evaluated for their sensitivity or specificity, and the comparison has usually been with another screening tool. ${ }^{[21]}$ Like Neelemaat et al. we have compared the tools with a preset definition to enable better generalization. ${ }^{[22]}$ We found that the prevalence of malnutrition was high by all three methods, clearly indicating the need for routine screening for risk of malnutrition.

For a screening tool, high sensitivity will ensure that patients at a true risk of malnutrition will not remain undiagnosed. Both tools showed a high sensitivity in

Table I: Sensitivity, specificity, and predictive values of the nutrition screening tools

\begin{tabular}{lcccc}
\hline & \multicolumn{4}{c}{$95 \% \mathrm{Cl}(\%)$} \\
\cline { 2 - 5 } & Sensitivity & Specificity & PPV & NPV \\
\hline MUST $96.5(87.9-99.5)$ & $72.3(57.5-84.5)$ & $80.9(69.5-89.4)$ & $94.4(8 I .3-99.1)$ \\
GNRI & $89.5(75.2-96.9)$ & $55.0(38.5-70.3)$ & $65.4(50.9-78.0)$ & $84.6(65.1-95.5)$ \\
\hline
\end{tabular}

Cl: Confidence interval; NPV: Negative predictive value; PPV: Positive predictive value; MUST: Malnutrition Universal Screening Tool; GNRI: Geriatric Nutrition Risk Index

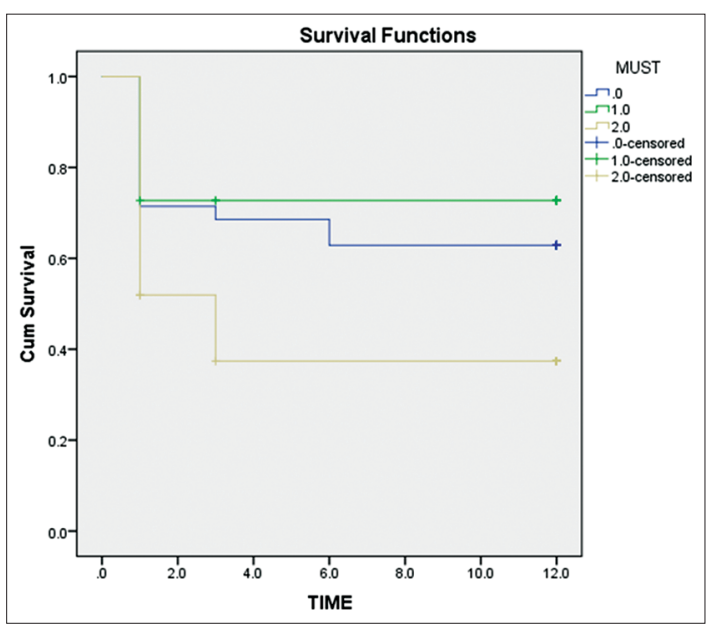

Figure 2: Test of survival distributions for the different levels of Malnutrition Universal Screening Tool. ${ }^{[4]}$ Log-rank (Mantel-Cox) $P=0.010$ 
our population. A low specificity (as we got for both tests) however, may result in over diagnosis of the risk of malnutrition.

The implications of an overdiagnosis of a malnourished state are difficult to predict with the current controversies regarding the appropriate amount of calories and proteins to be administered to ICU patients. A large prospective study by Alberda et al. involving more than 2770 patients concluded that increased protein and caloric intake improves outcomes in patients with when BMI is $<25$ or $\geq 35 .{ }^{[23]}$ Heyland et al. in an elegant multicentric prospective observational audit demonstrated that the statistical method employed in calculating the effect of nutrition on ICU patients affects the results - they concluded that an attempt to meet the estimated caloric requirements of the critically ill patient may result in improved outcomes. ${ }^{[24]}$ The EPaNIC, EDEN, and other large trials, on the other hand, suggest that early administration of larger protein or caloric loads to critically ill patients may be of no benefit or even harmful. ${ }^{[25-28]}$ Whether aggressive nutrition replacement should be done for critically ill patients screened as malnourished is not clear as these patients are not well represented in randomized clinical trials with the EPaNIC excluding patients with BMI $<17$, and Doig et al. having only 46 patients with a BMI <18.5. ${ }^{[29]}$ The results of Alberda et al., however, suggest that the effect of different levels of caloric intake may differ in patients with different underlying nutritional state; an easy to use, accurate assessment of the risk of malnutrition would be useful. Apart from the tools used by us, more recently, the NUTRIC tool has been described - it incorporates age, APACHE II score, Sequential Organ Failure Assessment score, number of comorbidities, days of hospital stay prior to ICU admission, and IL6 levels. It is used to quantify the risk of critically ill patients developing adverse events that may be modified by aggressive nutrition therapy. ${ }^{[30]}$

Apart from helping to identify the patient at a greater risk of preadmission malnutrition and related complications, a simple to use validated screening test tailored to a particular ICU and incorporated into its daily practise is also helpful in characterizing patients for research protocols and in increasing the awareness among medical personnel about nutritional issues. ${ }^{[1]}$

\section{Conclusion}

An easy to use screening test when used in the ICU to screen for malnutrition risk may alert the treating, team. Malnutrition, especially in the geriatric patients, has been associated with poorer long-term outcomes; in our population the MUST and GNRI screening tests may both be implemented successfully, with the MUST being better and easier to use.

\section{Acknowledgments}

The MUST is reproduced here with the kind permission of British Association for Parenteral and Enteral Nutrition. For further information on "MUST" see www.bapen.org.uk.

\section{Financial support and sponsorship Nil.}

\section{Conflicts of interest}

There are no conflicts of interest.

\section{References}

1. Sungurtekin H, Sungurtekin U, Okke D. Nutrition assessment in critically ill patients. Nutr Clin Pract 2008;23:635-41.

2. Feldblum I, German L, Castel H, Harman-Boehm I, Bilenko N, Eisinger M, et al. Characteristics of undernourished older medical patients and the identification of predictors for undernutrition status. Nutr J 2007;6:37.

3. Durán Alert P, Milà Villarroel R, Formiga F, Virgili Casas N, Vilarasau Farré C. Assessing risk screening methods of malnutrition in geriatric patients: Mini Nutritional Assessment (MNA) versus Geriatric Nutritional Risk Index (GNRI). Nutr Hosp 2012;27:590-8.

4. Tripathy S, Mishra JC, Dash SC. Critically ill elderly patients in a developing world - Mortality and functional outcome at 1 year: A prospective single-center study. J Crit Care 2014;29:474.e7-13.

5. Detsky AS, McLaughlin JR, Baker JP, Johnston N, Whittaker S, Mendelson RA, et al. What is subjective global assessment of nutritional status? 1987. Classical article. Nutr Hosp 2008;23:400-7.

6. Malnutrition Advisory Group. A consistent and reliable tool for malnutrition screening. Nurs Times 2003;99:26-7.

7. Ferguson M, Capra S, Bauer J, Banks M. Development of a valid and reliable malnutrition screening tool for adult acute hospital patients. Nutrition 1999;15:458-64.

8. Anthony PS. Nutrition screening tools for hospitalized patients. Nutr Clin Pract 2008;23:373-82.

9. Bouillanne O, Morineau G, Dupont C, Coulombel I, Vincent JP, Nicolis I, et al. Geriatric Nutritional Risk Index: A new index for evaluating at-risk elderly medical patients. Am J Clin Nutr 2005;82:777-83.

10. Malnutrition Universal Screening Tool. Available from: http://www. bapen.org.uk/pdfs/must/must_full.pdf. Last accessed 24/3/15.

11. Detsky AS, Smalley PS, Chang J. The rational clinical examination. Is this patient malnourished? JAMA 1994;271:54-8.

12. Kruizenga HM, Wierdsma NJ, van Bokhorst-de van der Schueren MA, Hollander HJ, Jonkers-Schuitema CF, Van der Heijden E, et al. Screening of nutritional status in The Netherlands. Clin Nutr 2003;22:147-52.

13. Stratton RJ, Green CJ, Elia M. Scientific criteria for defining malnutrition. In: Richards G, editor. Disease Related Malnutrition: An Evidence-Based Approach to Treatment. Cambridge: CABI Publishing; 2003. p. 1-34.

14. FAO/WHO/UNU. Energy and Protein Requirements, 724. Technical Report Series. Geneva: WHO; 1985.

15. Yamada K, Furuya R, Takita T, Maruyama Y, Yamaguchi Y, Ohkawa S, et al. Simplified nutritional screening tools for patients on 
maintenance hemodialysis. Am J Clin Nutr 2008;87:106-13.

16. Henderson S, Moore N, Lee E, Witham MD. Do the Malnutrition Universal Screening Tool (MUST) and Birmingham nutrition risk (BNR) score predict mortality in older hospitalised patients? BMC Geriatr 2008;8:26.

17. Stratton RJ, King CL, Stroud MA, Jackson AA, Elia M. 'Malnutrition Universal Screening Tool' predicts mortality and length of hospital stay in acutely ill elderly. Br J Nutr 2006;95:325-30.

18. Cereda E, Pedrolli C. The Geriatric Nutritional Risk Index. Curr Opin Clin Nutr Metab Care 2009;12:1-7.

19. Buzby GP, Knox LS, Crosby LO, Eisenberg JM, Haakenson CM, MeNeal GE, et al. Study protocol: A randomized clinical trial of total parenteral nutrition in malnourished surgical patients. Am J Clin Nutr 1988;47 2 Suppl: 366-81.

20. Shrout PE. Measurement reliability and agreement in psychiatry. Stat Methods Med Res 1998;7:301-17.

21. Chima CS, Dietz-Seher C, Kushner-Benson S. Nutrition risk screening in acute care: A survey of practice. Nutr Clin Pract 2008;23:417-23.

22. Neelemaat F, Meijers J, Kruizenga H, van Ballegooijen H, van Bokhorst-de van der Schueren M. Comparison of five malnutrition screening tools in one hospital inpatient sample. J Clin Nurs 2011;20:2144-52.

23. Alberda C, Gramlich L, Jones N, Jeejeebhoy K, Day AG, Dhaliwal R, et al. The relationship between nutritional intake and clinical outcomes in critically ill patients: Results of an international multicenter observational study. Intensive Care Med 2009;35:1728-37.
24. Heyland DK, Cahill N, Day AG. Optimal amount of calories for critically ill patients: Depends on how you slice the cake! Crit Care Med 2011:39:2619-26.

25. Casaer MP, Mesotten D, Hermans G, Wouters PJ, Schetz M, Meyfroidt G, et al. Early versus late parenteral nutrition in critically ill adults. N Engl J Med 2011;365:506-17.

26. Casaer MP, Wilmer A, Hermans G, Wouters PJ, Mesotten D, Van den Berghe G. Role of disease and macronutrient dose in the randomized controlled EPaNIC trial: A post hoc analysis. Am J Respir Crit Care Med 2013;187:247-55.

27. Doig GS, Simpson F, Sweetman EA, Finfer SR, Cooper DJ, Heighes PT, et al. Early parenteral nutrition in critically ill patients with short-term relative contraindications to early enteral nutrition: A randomized controlled trial. JAMA 2013;309:2130-8.

28. National Heart, Lung, and Blood Institute Acute Respiratory Distress Syndrome (ARDS) Clinical Trials Network, Rice TW, Wheeler AP, Thompson BT, Steingrub J, Hite RD, et al. Initial trophic vs. full enteral feeding in patients with acute lung injury: The EDEN randomized trial. JAMA 2012;307:795-803.

29. Casaer MP, Van den Berghe G. Nutrition in the acute phase of critical illness. N Engl J Med 2014;370:2450-1.

30. Heyland DK, Dhaliwal R, Jiang X, Day AG. Identifying critically ill patients who benefit the most from nutrition therapy: The development and initial validation of a novel risk assessment tool. Crit Care 2011;15:R268.

31. Preiser JC. Do we need an assessment of the nutrition risk in the critically ill patient? Crit Care 2012;16:101. 